\title{
TEMPO E DIREITO NA CONSTRUÇÃO DA SAÚDE ${ }^{1}$
}

Time and law to healthcare development

${ }^{1}$ Centro Universitário La Salle. Canoas/RS, Brasil.

${ }^{2}$ Faculdades Metropolitanas Unidas. São Paulo/SP, Brasil.

Correspondência: Germano A.D. Schwartz. E-mail: germano.schwartz@globo.com.

Recebido em: 28/11/2014. Aprovado em: 05/02/2015.

\footnotetext{
${ }^{1} \mathrm{O}$ presente artigo foi apresentado - e para ele escrito - durante o seminário “É tempo de pensar - e repensar - o Direito", realizado nos dias 25 e 26 de setembro de 2012, na Universidade do Vale do Rio dos Sinos (Unisinos), sob a organização de Marcos Catalan.
} 


\section{RESUMO}

De acordo com as tendências atuais da dogmática constitucionalista brasileira, a saúde, no direito, resta centralizada nas discussões de eficácia da norma e de suas consequências interpretativas no interior do sistema jurídico. O propósito deste estudo é o de verificar as relações entre tempo e direito na construção da saúde. Assim, seu foco está relacionado à forma pela qual o direito pretende controlar o tempo, especificamente na questão sanitária. Para tanto, a metodologia utilizada está alicerçada e repousa no funcionalismo estrutural de Niklas Luhmann, na vertente autopoiética de sua teoria dos sistemas sociais autopoiéticos. Os resultados demonstram que o sistema jurídico atua de forma paradoxal em relação à saúde, seja procurando dirigir-se ao futuro, seja prendendo-se ao passado para, no presente, construir uma descrição sociojurídica das comunicações sanitárias.

\section{Palavras-chave}

Direito; Luhmann; Saúde; Sistemas Autopoiéticos; Tempo.

\section{ABSTRACT:}

In accordance with current trends in the Brazilian constitutional doctrine, the discussions on health care as a right remain centered upon the efficacy of the law and the consequences of its different interpretations within the legal system. The purpose of this study is to verify the relationships between time and law in the development of the country's health care system. Thus, its focus is on the way in which the law attempts to control time, particularly concerning questions of health care. To this end, the methodology used is based on the structural functionalism of Niklas Luhmann and on the autopoietic aspect of his theory on autopoietic social systems. The results show that the Brazilian legal system acts in a paradoxical way when it comes to health care; it attempts to focus on the future but is stuck in the past when it attempts to develop a socio-juridical description of health care laws in the present.

\section{Keywords}

Autopoietic Systems; Health; Law; Luhmann; Time. 


\section{Introdução}

A literatura sobre direito à saúde cresceu de forma exponencial nos últimos anos no Brasil. Duas razões podem ser apontadas como principais para a ocorrência desse fenômeno: (a) a denominada judicialização da saúde e (b) a audiência pública realizada pelo Supremo Tribunal Federal (STF).

A primeira razão deve-se ao elevado número ${ }^{2}$ de ações relativas à prestação em saúde no Brasil. A crescente solicitação dos cidadãos ao Poder Judiciário por proteção de seu direito à saúde coloca os juízes em situações diversas. Gilmar Ferreira Mendes ${ }^{3}$, ao comentar sobre a atuação do STF em causas com esse objeto, afirma que tal fato: "espelha os dilemas cotidianos enfrentados pelos magistrados, especialmente na primeira instância, na medida em que esses juízes são colocados em situações de vida ou morte".

A segunda razão é resultado da primeira. O objetivo central da audiência pública foi ouvir técnicos, especialistas, usuários do Sistema Único de Saúde (SUS), juristas, entre outros, com o objetivo de esclarecer questões técnicas, científicas, administrativas, políticas, econômicas e jurídicas nas ações que dizem respeito à prestação sanitária .

Ambos os eventos estão relacionados ao fato de colocarem o problema do direito à saúde em uma visão singular: ela deve ser resolvida mediante os parâmetros utilizados pelo sistema jurídico, de acordo com sua auto-organização e por meio de seus pressupostos. Um sumário das respostas procuradas - e das quais outros questionamentos dela decorrem - por essa corrente, exemplificada por Scaff, é: "Seria o direito à saúde uma norma programática? Veicularia direitos passíveis de subsunção ao Poder Judiciário visando à obtenção de prestações individualizadas de saúde?"5.

Trata-se, a visão supracitada, de uma abordagem exclusivamente heteropoiética, proveniente do que se pode chamar de sistema fechado, ou, ainda, de uma observação de primeira ordem sobre uma comunicação - saúde - presente no ambiente dos subsistemas sociais. É nesse sentido que a distinção entre sistema e ambiente é essencial na teoria dos sistemas sociais, pois ela aborda "not only the knowledge that there is an environment, but also the insight that an open system

\footnotetext{
${ }^{2}$ Segundo dados do Conselho Nacional de Justiça, o Brasil possui, hoje, mais de 240 mil processos na área da saúde. BRASIL tem mais de 240 mil processos na área de Saúde. Disponível em: <http://www.cnj.jus.br/ noticias/cnj/14096-brasil-tem-mais-de-240-mil-processos-na-area-de-saude>. Acesso em: 03 set. 2012.

${ }^{3}$ MENDES, Gilmar Ferreira. Introdução. Audiência Pública - Saúde. Brasília: Supremo Tribunal Federal, 2009.

${ }^{4}$ VALLE, Gustavo Henrique Moreira do; CAMARGO, João Marcos Pires. A audiência pública sobre a judicialização da saúde e seus reflexos na jurisprudência do Supremo Tribunal Federal. Revista de Direito Sanitário, São Paulo, v. 11, n. 3, p. 16, nov. 2010/fev. 2011.

${ }^{5}$ SCAFF, Fernando Facury. O direito à saúde e os Tribunais. In: NUNES, Antônio José Avelãs; SCAFF, Fernando Facury (Orgs.). Os Tribunais e o direito à saúde. Porto Alegre: Livr. do Advogado, 2011. p. 129.
} 
is based on the relations between system and environment and that these relations are not static but dynamic; they are, as it were, channels that conduct causality"6.

Nesse sentido, entende-se, no presente ensaio, insuficiente descrever o direito à saúde de uma maneira fechada. É preciso, como refere Teubner ${ }^{7}$, recordar que a clausura normativa do sistema jurídico depende, umbilicalmente, de sua abertura cognitiva. A partir disso, tem-se que o direito possui estrita conexão com a saúde ${ }^{8}$ - e vice-versa -, restando impossível, em uma análise complexa, reduzir suas variáveis ao plano estritamente normativo.

Seguindo essa linha de raciocínio, a delimitação da abordagem realizada está localizada nas relações entre tempo e direito e focada na questão da saúde. Em outras palavras: de que modo o direito tenta controlar o tempo e de que forma isso é feito no caso da saúde a partir do plano constitucional?

Com isso em mente, ao final, abordam-se os paradoxos de tal interconexão, úteis para uma observação de segunda ordem sobre o direito à saúde, calcados no fato de que decisões judiciais são realizadas no presente, porém baseadas em dados passados (leis, ocorrências de saúde, entre outros) para que, no futuro, a violação da norma (estabilização de expectativas) sanitária não se repita.

\section{0 tempo e o direito}

Existem várias concepções a respeito do tempo: físicas, historicistas, biológicas, entre outras. Dentro do recorte proposto, o artigo terá como ponto central a questão de como tempo e direito se relacionam na questão jurídica a partir do viés da teoria dos sistemas autopoiéticos de Niklas Luhmann.

Um dos pontos a serem observados a respeito disso é que direito e tempo são construções sociais. Dois exemplos clássicos dão sustento ao argumento:

(a) em 15 de outubro de 1582, os povos católicos - incluindo o Brasil - iniciaram o uso do calendário gregoriano em detrimento do juliano. Havia um erro de dez dias neste último que precisava ser corrigido. Eles foram omitidos e os dias compreendidos entre 5 e 14 de outubro daquele ano deixaram de existir. Um novo tempo. Um calendário civil até hoje vigente e que fez sumir dez dias;

(b) de outro lado, na Revolução Francesa, um novo calendário foi adotado em 1792. Possuía 12 meses de 30 dias. Cada mês era composto de três semanas de dez dias (decâmeros ou décadas). Para completar o ano, eram inseridos mais cinco ou seis dias - se bissexto. O dia tinha dez horas distribuídas em cem partes.

\footnotetext{
${ }^{6}$ LUHMANN, Niklas. System as difference. Organization, London, v. 13, n. 1, p. 38, 2006.

${ }^{7}$ TEUBNER, Gunther. 0 direito como sistema autopoiético. Lisboa: Calouste Gulbenkiam, 1989. p. 67.

${ }^{8}$ SCHWARTZ, Germano. A autopoiese do sistema sanitário. Revista de Direito Sanitário, São Paulo, v. 4, n. 1, p. 50-59, 2003
} 
Seu objetivo maior era romper com o passado e, para isso, literalmente, um novo tempo era necessário.

Significa que ambos (tempo e direito) possuem uma função na sociedade. A elaboração de uma norma jurídica contém, intrinsecamente, uma expectativa social. E ela está ligada a uma relação necessariamente temporal. Nas palavras de Leonel Severo Rocha: "o Tempo é uma instituição social e nesse sentido depende do direito. O direito é uma estrutura da sociedade e assim configura a continuidade da ação social na forma de sociedade dominante"

Em Kelsen, por exemplo, direito e tempo estão essencialmente ligados na questão da normatividade, pois o direito é "uma ordem normativa da conduta humana, ou seja, um sistema de normas que regulam o comportamento humano"10. De fato, ele seria o cruzamento entre o presente (a estática jurídica) e a história (dinâmica jurídica), baseado que está no conceito de validade ${ }^{11}$. Para os defensores dessa maneira de observar o tempo no direito, cedo ou tarde, mantendo-se certos critérios procedimentais, os resultados da norma aparecerão conforme seu esquema dever-ser ${ }^{12}$. A questão do controle temporal, assim, é essencial nessa abordagem do sistema jurídico.

Entre vigência e validade, portanto, a dogmática jurídica se estabelece, delimitando temporalmente seu campo de atuação, o que requer, por exemplo, que todas as normas jurídicas sejam publicadas em determinado tempo. Relações de anterioridade e posterioridade são estabelecidas para resolver eventuais conflitos normativos. Logo, a normatividade é a capacidade de construir tempo (social). De outro lado, François $O s t^{13}$, ainda na linha de que o direito é construção social, caracteriza-o a partir de uma divisão quadripartida. A saber:

(a) Memória: uma das grandes funções do direito é armazenar a memória da sociedade, como é o caso, por exemplo, dos tabeliães e dos notários. É, claramente, um movimento em direção ao passado e sua reafirmação no presente.

A memória, gize-se, também para De Giorgi $i^{14}$, funciona como um filtro entre recordar e esquecer. Sua função mais importante, de acordo com Luhmann ${ }^{15}$, é a de reprimir eventos passados, isto é, esquecer-se do que não é importante, liberando o sistema (jurídico) para operações futuras.

\footnotetext{
${ }^{9}$ ROCHA, Leonel Severo. A construção do tempo pelo direito. In: ROCHA, Leonel Sevro; STRECK, Lenio Luiz (Orgs.). Anuário do Programa de Pós-Graduação em Direito. Mestrado e Doutorado. 2003. São Leopoldo: Unisinos, 2003. p. 312.

${ }^{10}$ KELSEN, Hans. Teoria pura do direito. 6. ed. São Paulo: Martins Fontes, 1998. p. 5.

${ }^{11}$ ROCHA, Leonel Severo; Francisco Carlos Duarte. O direito e o tempo social. In: ROCHA, Leonel Severo; Francisco Carlos Duarte. (Orgs.). A construção sociojurídica do tempo. Curitiba: Juruá, 2012. p. 17.

${ }^{12}$ LUHMANN, Niklas. Das Recht der Gesellschaft. Frankfurt: Suhrkamp, 1997. p. 558.

${ }^{13}$ OST, François. O tempo do direito. Lisboa: Piaget, 1999.

${ }^{14}$ DE GIORGI, Rafaelle. Direito, tempo e memória. São Paulo: Quartier Latin, 2006. p. 20-34.

${ }^{15}$ LUHMANN, Niklas. Introduccíon a la teoría de sistemas. México: Universidad Iberoamericana, 2004. p. 224.
} 
(b) Perdão: é a capacidade de o direito esquecer-se daquilo que ocorreu, temporalmente, no passado. Sem isso, ele resta preso a uma ocorrência anterior e não produz efeitos futuros. O perdão não é generalizado (pena de morte). Ele é seletivo e para determinados fatos.

(c) Promessa: ela rompe com a tradição e está essencialmente ligada ao futuro, isto é, às possibilidades de construção temporais diversas das presentes e das passadas por meio do direito.

(d) Questionamento: é o momento último, aquele que liga a promessa ao perdão e à memória.

Assim, para que se construa um novo tempo no direito, é preciso, antes, desinstitucionalizar o instituído para que haja uma nova reinstitucionalização, agora do novo. A velocidade com que esse movimento se dá, define claramente a função temporal do direito. Quanto mais lento, menor conexão com uma descrição social de futuro ${ }^{16}$.

Essa é a expectativa de expectativas. Complexidade, para $\mathrm{Luhmann}^{17}$, significa dizer que "sempre existem mais possibilidades do que se pode realizar". Já a contingência reside no fato de que "as possibilidades apontadas para as demais experiências poderiam ser diferentes das esperadas".

Em outras palavras: complexidade é seletividade forçada; a contingência tem como intrínseca a possibilidade de desapontamento. Daí que surge outra variável essencial no pensamento luhmanniano: o risco. $\mathrm{O}$ risco está ligado à contingência e torna inegável sua presença.

Essa seletividade forçada é feita pelos sentidos do homem, visando a uma imunização do risco. A expectativa, com isso, toma relevo, ancorada nas identidades apreendidas dos sentidos (coisas, homens, eventos...). Ela é, desde outro ponto de vista, a possibilidade de se ver com os olhos dos outros e aumenta a seletividade imediata da percepção.

Isso faz com que o risco esteja potencializado, forçado pela dupla contingência do mundo social: somente se reconhecem expectativas por meio das expectativas de um outro. Se alguém erra, o outro também pode errar. Essa dupla contingência necessita de uma estrutura de expectativas muito mais complicada do que nas sociedades de contingências simples: a expectativa de expectativas ${ }^{18}$.

E é na interseção entre a expectativa e a expectativa que se possui a respeito da expectativa de outrem que reside a função temporal da norma jurídica. É preciso

\footnotetext{
${ }^{16}$ ROCHA, Leonel Severo; Francisco Carlos Duarte. op. cit., p. 20

${ }^{17}$ LUHMANN, Niklas. Sociologia do direito I. Rio de Janeiro: Tempo Brasileiro, 1983. p. 45.

${ }^{18}$ Id. Ibid., p. 47.
} 
que a decisão dada considere a necessidade de redução dessa complexidade, levando em consideração seu caráter contrafático ${ }^{19}$.

A partir daí, a estratégia é a fixação antecipada da forma de reação. Dito de outro modo: antecipar o futuro e ao mesmo tempo minimizar os riscos. Isso é feito mediante a sustentação de uma contradição: a possibilidade do desapontamento pode ocorrer. E, quando ocorrer, poderá ser tanto benéfica quanto maléfica, dependendo do ponto de vista do observador. Somente assim se realizará uma menor complexidade interna do sistema, encobrindo-se a possibilidade do comportamento oposto.

Assinale-se, entretanto, que a análise do tempo é distinção. Inexiste, nessa relação, uma posição privilegiada e/ou um observador último. Há uma distinção secundária em relação ao tempo, que é sua condição paradoxal de avanço. Trata-se das coisas mutáveis ou imutáveis ${ }^{20}$. Dito em outras palavras: é muito mais compreensível que o imutável possa ser observado pelo observador, visto que é desnecessária uma nova mirada. Não há o que descobrir. As coisas são assim. O que se pode mudar somente se pode mudar a partir da existência do imutável.

Tal é o esquema, em largas linhas, do dogmatismo jurídico, preso que está em um momento do passado, facilmente observável e com o qual os juristas se relacionam sem maiores dificuldades. Isso porque jurisprudências, doutrinas e decisões de caráter jurídico reforçam, ainda mais, a imutabilidade no sentido de que fazem o reinforcement da lei.

Da mesma forma, verificar que um dos grandes problemas das decisões judiciais na área da saúde encontra-se, precisamente, na questão da mutabilidade/imutabilidade não é algo difícil. No momento em que se baseia na norma jurídica (imutável), abrem-se para o julgador dois caminhos: a manutenção de uma possibilidade futura de avanço de saúde ou da permanência do status quo dela. Em muitas das vezes, todavia, isso significa decidir, conforme já explicitado, a partir de outro binômio: vida/morte.

Ocorre, porém, que há outra distinção temporal necessária ${ }^{21}$. Acaso se consiga aceitar que exista um momento no tempo em que não há como aferir à existência do tempo, pode-se criar outra relação distintiva. Esse momento é o presente. Ele não existe. Já passou. Acabou de se esvair. Como referem Leonel Severo Rocha e Francisco Carlos Duarte: "o tempo é a sucessão contínua de instantes nos quais se desenvolvem eventos e variações das coisas" 22 .

Mas é ele, o presente, necessário? Sim, tal como o décimo segundo camelo, elemento fundante do sistema jurídico ${ }^{23}$. Ele é o ponto de partida para a diferença

\footnotetext{
${ }^{19}$ LUHMANN, Niklas. Sociologia do direito I, cit., p. 57.

${ }^{20}$ Id. La sociedad de la sociedad. México: Herder, 2007. p. 714.

${ }^{21}$ Id. Ibid., p. 714.

${ }^{22}$ ROCHA, Leonel Severo; Francisco Carlos Duarte. op. cit., p. 15.

${ }^{23}$ LUHMANN, Niklas. Introduccíon a la teoría de sistemas, cit., p. 33-108.
} 
entre passado e futuro ${ }^{24}$. Entre estes nada há. Sob a perspectiva da teoria dos sistemas autopoiéticos, somente no presente é que se podem atualizar as operações de observação. O presente é a unidade não observável da diferença ${ }^{25}$. Ele é visto como uma diferença de horizontes temporais que, em cada um dos casos, não é atual. Destemporaliza-se, assim, a observação do tempo.

O tempo, por exemplo, para $\mathrm{Clam}^{26}$, está intimamente ligado à ideia de autopoiese, uma sucessão de eventos contínuos coligados entre operações e estruturas para o acontecimento, no direito, da função do sistema jurídico: decidir, mediante seus critérios de organização e de legitimação ${ }^{27}$, os casos que lhes são postos. A legitimidade do sistema jurídico repousa, pois, no reconhecimento de suas decisões como obrigatórias, utilizando-se para tanto seus procedimentos operativos.

Nessa linha de raciocínio, levando-se em consideração que o sistema jurídico está influenciado por - e dirigido para - uma função normativa (sem ela não seria direito), Luhmann $^{28}$ refere que ele possui dois modos de temporalização: (a) a da validade normativa e (b) a da complexidade.

No caso da temporalização da validade normativa, as normas não estão mais fundamentadas em critérios religiosos, morais e éticos. Elas encontram assento em suas projeções de tempo. Sua validade é provisória e, portanto, contingente. Em uma sociedade em constante movimentação, de proliferação de riscos, as expectativas lançadas em relação ao direito são diferentes.

Quando se parte do pressuposto de que a sociedade atua como elemento essencial do sistema jurídico, já que este faz parte dela, abandona-se a ideia de direito como destino individual. Espera-se prevenção e, assim, na linguagem de Luhmann ${ }^{29}$, o sistema jurídico almeja um futuro certo em uma distinção do provável/improvável sem orientações naturalistas e/ou positivistas.

Desse modo, há que se entender o fato de as expectativas normativas assumirem, novamente, um alto grau de importância, visto que a variabilidade do sistema jurídico é inerente a ele. Em outras palavras: o próprio sistema jurídico encontra mecanismos de variação temporal e de distribuição de riscos. É o caso, por exemplo, dos contratos, locais em que a desconfiança de que no futuro existam violações a suas cláusulas fundamenta a confiança presente.

\footnotetext{
${ }^{24}$ LUHMANN, Niklas. Sistemas sociales: lineamientos para una teoría general. México: Alianza; Universidad Iberoamericana, 1991. p. 315.

${ }^{25}$ Id. La sociedad de la sociedad, cit., p. 715.

${ }^{26}$ CLAM, Jean. Questões Fundamentais de uma teoria da sociedade: contingência, paradoxo, só-efetuação. São Leopoldo: Ed. Unisinos, 2006. p. 143-151.

${ }^{27}$ LUHMANN, Niklas. Legitimação pelo procedimento. Brasília: Ed. da UnB, 1980. p. 32.

${ }^{28}$ Id. Das Recht der Gesellschaft, cit., p. 557-565.

${ }^{29}$ Id. Ibid., p. 559.
} 
Logo, o sistema jurídico não possui condições de promover segurança, e sim de amenizar riscos. E o risco é uma forma de controle temporal, pois este se trata de decisões que vinculam o tempo, ainda que não se possa conhecer suficientemente o futuro e muito menos o futuro produzido pelas decisões tomadas ${ }^{30}$. O risco não garante sua imutabilidade. Mas absorve, contudo, uma forma jurídica específica para decidir a respeito, baseada nos seguintes pressupostos $^{31}$ :

(a) a função da manutenção das expectativas normativas por parte do sistema jurídico está vinculada aos custos sociais de suas vinculações temporais, mas não é necessário que isso esteja expresso nas normas jurídicas. O controle da temporalidade é característica inerente ao sistema jurídico.

(b) A validade jurídica é algo dinâmico e repousa em um movimento circular em que o sistema jurídico, momentaneamente, por suas decisões, revela seu estado atual.

(c) O problema das decisões jurídicas reside no fato de que as argumentações expendidas pelos juristas não levam em consideração sua temporalidade, postulando a continuação da pretensão de segurança. A quase completa ausência de interpretações baseadas na probabilidade/improbabilidade de decisões válidas no tempo demonstra o descompasso cronológico dos operadores de direito.

(d) O sistema jurídico, do ponto de vista temporal, não baseia sua racionalidade no legislador como queria, por exemplo, a escola positivista de direito. A racionalidade, em uma sociedade democrática e inclusiva de atores outros no processo de elaboração das normas jurídicas, está na multiplicação das possibilidades (audiência pública do STF sobre a saúde) para a ampliação das margens de decisão, incrementando-se, com isso, as limitações decisórias relativas ao tempo.

Nesse sentido, para Arnaud ${ }^{32}$, a sociedade resultante da globalização possui vários espaços de decisão normativos que não são provenientes unicamente do Estado. Assim, o dizer o direito é uma tarefa compartilhada e compreendida na lógica bottom up, em substituição ao procedimento clássico top down.

De outra banda, no caso da temporalização da complexidade, está-se diante de um problema de imunização, via autopoiese, do sistema jurídico. Trata-se de buscar, por meio de uma redução de complexidade de seu entorno, onde está a saúde, construindo sua própria complexidade, em um movimento que une a clausura normativa aos acoplamentos estruturais.

Assim, o sistema jurídico estabelece sua auto-organização, sua autorreprodução e sua recursividade. Com isso, ele consegue manter sua temporalização

\footnotetext{
${ }^{30}$ LUHMANN, Niklas. Sociologia del riesgo. México: Triana, 1993. p. 55-56.

${ }^{31}$ Id. Das Recht der Gesellschaft, cit., p. 562-564.

${ }^{32}$ ARNAUD, André-Jean. Governar sem fronteiras: entre globalização e pós-globalização crítica da razão jurídica. Rio de Janeiro: Lumen Juris, 2007. v. 2.
} 
e elabora estruturas que neutralizam perturbações imprevistas. É dessa maneira que o sistema social consegue, mediante seus subsistemas, fazer frente à constante reprodução de conflitos nele existentes ${ }^{33}$.

Sem conflitos inexiste o direito. Eles são formas de aprendizagem para o sistema jurídico. Também, claro, podem ser gerados pelo próprio direito (antinomias, divergências jurisprudenciais, entre outros). Mas a regra jurídica, quando pronta, não é conflito. Ela é a causadora de conflitos. É deles. Controla-os, portanto, temporalmente, quem a respeito dela decide (sistema jurídico).

Assim, em uma sociedade complexa, o desenlace cronológico dos conflitos a respeito das normas jurídicas é dado pelo direito mediante suas programações condicionais e por meio de seu código específico (Recht/Unrecht $)^{34}$. Tal raciocínio é aplicável, pois, aos conflitos a respeito das normas jurídicas relativas à saúde.

Nessa esteira, a partir das distinções estabelecidas, e iniciando pela primeira (sistema $\mathrm{x}$ ambiente), o problema da construção temporal da saúde via direito está inserido no interior das estruturas de expectativas normativas relativas ao direito à saúde. Dito de outro modo: a saúde possui uma construção temporal dada pelo direito que é reflexiva e, portanto, auto-observa ou seu caráter mutável/imutável ou sua distinção inovadora/não inovadora. Daí que se torna imprescindível verificar como, no Brasil, as expectativas normativas estão orientadas para o controle temporal da saúde.

\section{De que forma o direito controla o tempo da saúde?}

Toda decisão produz tempo ${ }^{35}$. No direito, isso não é diferente, muito menos no caso do direito à saúde. $\mathrm{O}$ direito possui um tempo próprio, diferente do social. A questão é ajustá-lo, para que não ocorra o que $O s t^{36}$ denomina de risco de diacronia. Esse é o drama da denominada judicialização da saúde.

Magistrados, gestores públicos, cidadãos, enfim, todos aqueles envolvidos no processo decisório compartilhado em relação à proteção da saúde, encontram-se em um dilema temporal ${ }^{37}$. O que será decidido deve se orientar ao futuro ou ao passado. E o problema presente?

Como a resposta não pode ser retirada de outro sistema que não o jurídico, visto que o problema central deste artigo está relacionado ao direito e à saúde, é

\footnotetext{
${ }^{33}$ LUHMANN, Niklas. Das Recht der Gesellschaft, cit., p. 567.

${ }^{34}$ Id. Ibid., p. 568.

${ }^{35}$ Id. Sistemas sociales: lineamientos para una teoría general, cit., p. 195-197

${ }^{36}$ OST, François. op. cit., p. 17.

${ }^{37}$ SCHWARTZ, Germano. Gestão compartida sanitária no Brasil: possibilidade de efetivação do direito à saúde. In: SCHWARTZ, Germano (Org). A saúde sob os cuidados do direito. Passo Fundo: UPF Ed., 2003. p. 108-162.
} 
preciso perscrutar sobre quais programas se assenta a comunicação a respeito. Em outro ângulo: existem formas de programação dadas pelo sistema jurídico para a saúde atuar em seu controle temporal? A partir disso, pode-se verificar qual a orientação de produção de sentido das expectativas normativas relativas à saúde em solo brasileiro.

É preciso, antes, compreender que a saúde, enquanto sistema e tanto quanto o direito, necessita de uma temporalização da complexidade. Nessa esteira, não há dúvidas de que o âmbito sanitário é eivado de complexidade. Hipercomplexidade. $\mathrm{O}$ risco está sempre presente, inclusive pelas razões paradoxais apontadas por Moreau e por Truchet ${ }^{38}$. O próprio avanço da saúde traz problemas para seu avanço (futuro) e/ou sua manutenção (passado). Algumas delas são:

(a) a revolução tecnológica modificou a atitude do homem perante a morte. De fato, deu-lhe maior confiança em critérios maiores de previsibilidade com relação a seu futuro. Logo, a atenção à saúde passou a ocupar um espaço maior em suas preocupações cotidianas, resultando em um aumento da expectativa de vida, o que, paradoxalmente, faz surgirem outros problemas, pois sistemas de saúde devem desenvolver novas formas de atenção para um grupo cada vez maior de pessoas que necessitam, mais e mais, de atenção médica.

(b) A revolução científica transformou a mentalidade e o comportamento do médico. O binômio científico falso/verdadeiro, apoiado no desenvolvimento de tecnologias, possibilitou ao homem não mais a certeza da infinitude, mas uma probabilidade de negação do infinito.

(c) Nos países desenvolvidos, a revolução médica criou uma melhoria sensível da saúde que precisa ser mantida. Gastos são necessários. Demandas são potencializadas. Um maior número de pessoas é incluído nos sistemas de saúde. Uma complexidade que se potencializa rotineiramente pela própria evolução do sistema sanitário.

Nessa esteira, é a própria autopoiese do sistema sanitário que tornará possível a redução de complexidade e, mais, o controle temporal que ele pretende. Claro, isso dentro de suas limitações e a partir de suas próprias orientações. No caso da saúde, o modo como os médicos agem é um sinônimo para sua clausura ${ }^{39}$. Os diagnósticos possuem um alto índice de incerteza e insegurança, e saber as estruturas que os guiam é entender o funcionamento interno do sistema sanitário.

Dessa forma, tal quais os demais subsistemas sociais, o sanitário possui uma função, que é de curar. Assim, ninguém pode se curar fora dele, a não ser que o faça

\footnotetext{
${ }^{38}$ MOREAU, Jacques; TRUCHET, Didier. Droit de la santé publique. Paris: Dalloz, 2000.

${ }^{39}$ LUHMANN, Niklas. Sociologische Aufklärung 5: konstruktivistische perspektiven. Opladen: Westedeutscher Verlag, 1993. p. 188.
} 
sem saber e por si só. No mesmo caminho, seu código lhe dá clausura operativa e abertura cognitiva.

Adotando-se essa premissa, já se obtêm uma redução de complexidade e uma relação de controle temporal. Excluindo-se valores terceiros que não sua função e seu código, o sistema sanitário está apto para desenvolver sua operatividade. $\mathrm{O}$ código facilita suas operações recursivas e possui, sempre, um polo negativo e outro positivo, tal é a exclusividade de um subsistema. Acaso outro atue nesse âmbito, há um problema de sobreposição de subsistemas e a perda de função de um deles.

No caso da saúde, significa que não se pode pensar exclusivamente nela. Ao contrário dos demais subsistemas sociais, é seu polo negativo (enfermidade) que orienta o susbsistema de saúde ${ }^{40}$. A doença é, portanto, o equivalente funcional da saúde. A saúde não é o ponto de enlace do sistema e, de outra banda, a enfermidade não é o ponto de reflexão - e sim, de ação.

Desse modo, no sistema sanitário, o alvo dos médicos e dos pacientes não reside na saúde, e sim na doença. A prática tende do positivo para o negativo. $\mathrm{O}$ objetivo é a libertação das doenças. Daí que a temporalização da complexidade da saúde resta bastante evidente: (a) a doença é atual (presente); (b) a doença não é futuro nem passado. É um ponto distintivo; e (c) o diagnóstico, portanto, baseado no presente (doença), necessita buscar um futuro diverso do passado.

De outro lado, no que tange à temporalização da validade normativa do direito à saúde, é preciso, como já dito, verificar as expectativas normativas sobre a questão da saúde no Brasil. Tome-se como ponto de partida o fato de que se trata de um direito recente no sistema jurídico pátrio, inscrito que foi, pela primeira vez, na Constituição Federal de $1988^{41}$.

A organização do SUS foi antecedida por várias discussões na sociedade brasileira $^{42}$. Assim, representa um momento de ruptura com o passado destinado a, no futuro, satisfazer as expectativas daquele presente. E isso foi realizado, como sói acontecer, por meio da legislação (expectativas normativas).

Como lembra Tojal ${ }^{43}$, o SUS representa um novo futuro. Nele, todos os poderes públicos e a sociedade estão vinculados aos objetivos constitucionais

\footnotetext{
${ }^{40}$ LUHMANN, Niklas. Therapeutische Systeme - Fragen an Niklas Luhmann. In: SIMON, F.B. (Hg.). Lebende Systeme. Wirklichkeistskonstruktionen in der Systemichen Therapie. Berlin: Heidelberg - New York u.a., 1988. p. 127.

${ }^{41}$ SCHWARTZ, Germano. Direito à saúde: efetivação em uma perspectiva sistêmica. Porto Alegre: Livr. do Advogado, 2001. p. 43-48.

${ }^{42}$ SOUZA, Renildo Rehem. O sistema público de saúde brasileiro. Brasília: Ministério da Saúde, 2002. p. 29.

${ }^{43}$ TOJAL, Sebastião Botto de Barros. O direito regulatório do Estado Social e as normas legais de saúde pública. Brasília: Organização Pan-Americana de Saúde: Escritório Regional da Organização Mundial de Saúde: Representação do Brasil, 1994. p 22. (Série Direito e Saúde, n. 4).
} 
sanitários. A saúde é, portanto, portadora de uma expectativa transformadora, representante de um futuro que se deseja(va) construir por meio, também, do sistema jurídico.

Nessa esteira, a Constituição Federal de 1988, em seu artigo 196, forneceu o desenho temporal da saúde como direito no Brasil. Ao dizer que ela é direito de todos e dever do Estado, estabeleceu as relações entre credor (cidadão) e devedor (Estado). É dessa inter-relação que surgem, principalmente, as discussões heteropoiéticas - e que não interessam aqui - da judicialização da saúde.

Ao mesmo tempo, todavia, o artigo em tela define que a saúde será garantida por meio de políticas sociais e econômicas que visem à redução do risco. O texto constitucional aceita, claramente, que se está diante de um fenômeno contingente cuja redução de complexidade somente é possível mediante a compreensão dos problemas da saúde pelo sistema sanitário e a resolução dos problemas judiciais a seu respeito com base nos pressupostos do sistema jurídico - obedecendo, cada qual, a sua clausura operativa e a sua abertura cognitiva. É a distinção sistema $\mathrm{x}$ ambiente que proporciona, mediante comunicações e por meio da autopoiese, o controle temporal tanto da saúde quanto do direito.

Seguindo, o artigo 196 da Constituição Federal de 1988 refere que as ações e os serviços de saúde estão orientados para a promoção, proteção e recuperação da saúde. De fato, aqui se apresenta, com maior rigor, a temporalização da validade normativa da saúde no Brasil.

Note-se que dois dos três elementos, assim como no sistema sanitário, são orientados pela doença. Dessa maneira:

(a) a proteção ocorre em um momento anterior à ocorrência da doença no ser humano e está relacionada ao caráter curativo. Antecipa-se a um futuro que pode ser controlado mediante tecnologias e conhecimento (ciência), prologando temporalmente o inevitável (a doença).

(b) A recuperação está posicionada após o acontecimento da doença. Procura pelo restabelecimento do status quo, visando ao alcance de uma condição futura em que a doença não mais persista ou, ao menos, seja minimizada.

(c) O terceiro elemento, a promoção, é conectado a uma ocorrência temporal futura. Trata-se da busca pela qualidade de vida. Nesse caso, todavia, busca-se uma saúde pela saúde. É uma visão salutogênica que não abre mão, entretanto, de estratégias temporais de consecução de seus objetivos.

Nesse sentido, verifica-se que a temporalização da validade normativa da saúde é inegável, dado o que prevê o texto constitucional. Tal normativa é orientada para a ruptura de um passado no qual não havia sua positividade para um futuro em que ocorram menos doenças e, por consequência, haja evoluções no sistema 
sanitário. Uma atuação contrária do sistema jurídico reproduziria um passado para o qual as expectativas normativas da sociedade brasileira não mais se dirigem.

\section{Observações (nunca finais): o tempo e o direito na construção da saúde}

Conforme referido anteriormente, as expectativas normativas em relação à saúde no quesito temporal procuram evitar a distância entre o tempo da saúde e o tempo do direito. É a diacronia, que ocorre, por exemplo, quando decisões em direito à saúde não são capazes de produzir futuro, como no caso de fornecimento de medicamentos para pacientes que deles não mais precisam porque já faleceram.

Dessa maneira, é preciso levar em consideração que uma das características da temporalização baseia-se na mutabilidade, em contraponto à pretensa imutabilidade. O problema reside, por exemplo, no fato de que correntes positivistas do direito fundam sua vigência na estática do sentido das normas. Partem delas, especialmente, os problemas decisórios temporais já aventados no direito à saúde.

É bastante simples trazer essa linha de raciocínio para a saúde. Veja-se um exemplo: as listas de dispensação de medicamentos são utilizadas pelo poder público como uma maneira de observar o imutável. Doenças possuem um tratamento idealizado e o Estado passa a ter a obrigação, mediante protocolos clínicos, de fornecer as drogas correspondentes para satisfazer, note-se, não a saúde das pessoas, mas sim seu dever de prestar a saúde.

Esse é apenas um exemplo na área da relação entre direito e saúde, na qual a relação temporal entre ambos se baseia no imutável. Tanto isso se mostra problemático quanto se sabe que a saúde é um sistema em que a mutabilidade é a base de seu avanço em direção ao futuro. Pesquisas com novas drogas são feitas diariamente; avanços tecnológicos são trazidos para a melhoria da qualidade de vida das pessoas, entre outros benefícios, e impelem o sistema sanitário para a busca da mutabilidade.

Nesse sentido, quando se estabelecem marcos de direito (normatividade), o próprio ato legislativo já é carregado de expectativas. No caso da saúde mais ainda, pois, como se sabe, a colocação desse tema na Constituição Federal de 1988 como direito fundamental foi uma inovação no sistema jurídico brasileiro que, outrora, jamais a havia alçado a tal patamar ${ }^{44}$.

Além do olhar lançado sobre a incidência de uma nova comunicação proveniente do sistema político (Constituição, Lei do SUS, entre outras) perante o sistema jurídico, o fato é que alçar a saúde à categoria de direito fundamental representou,

\footnotetext{
${ }^{44}$ SCHWARTZ, Germano. Direito à saúde: efetivação em uma perspectiva sistêmica, cit., p. 43-48
} 
temporalmente, um rompimento com o passado e um movimento em direção a um futuro tendente a favorecer novas conquistas democráticas ${ }^{45}$.

Do mesmo modo, na medida em que há a violação do direito à saúde - e, paradoxalmente, seu descumprimento será necessário para sua afirmação ${ }^{46}$, nasce outro tipo de expectativa. De que maneira a organização interna do sistema jurídico decidirá sobre os casos de direito à saúde que lhes são apresentados: em direção à afirmação de um futuro ou orientado pelo passado ${ }^{47}$ ?

Quando uma decisão em direito à saúde é tomada, ela pode seguir uma programação condicional ou uma programação finalística. Ao se optar pela primeira, baseada na repetição (súmulas, jurisprudências, entre outros), acentua-se o passado. De outro lado, ao se escolher a segunda, marcada pela produção de diferença e mediante critérios de distinção já elencados, a produção de tempo é notada de maneira mais consistente, muito embora uma decisão jurídica necessite de ambas as programações para ser válida ${ }^{48}$.

Como refere Luhmann $^{49}$, a dinâmica dos desenvolvimentos técnicos e científicos, entre os quais as inovações vitais provenientes das indústrias farmacêuticas e da tecnologia dos aparelhos médicos, torna evidente o fato de que a validade temporal da norma sanitária é conectada com um futuro em aberto, e não com um passado clausurado na temporalidade normativa.

Isso não significa dizer que a escolha pelo futuro pode ser certa. O desapontamento com relação à norma é intrínseco à operatividade interna do sistema jurídico. Assim, quem contrata um plano de saúde ou utiliza o SUS é sabedor, de antemão, de que não há garantia de vida, por exemplo, mas também de que, paradoxalmente, a doença será tratada. É um cálculo em contrário. Sem ele, o futuro não se concretiza.

\section{Referências}

ARNAUD, André-Jean. Governar sem fronteiras: entre globalização e pós-globalização crítica da razão jurídica. Rio de Janeiro: Lumen Juris, 2007. v. 2.

BRASIL tem mais de 240 mil processos na área de Saúde. Disponível em: <http://www.cnj. jus.br/noticias/cnj/14096-brasil-tem-mais-de-240-mil-processos-na-area-de-saude $>$.

\footnotetext{
${ }^{45}$ CAMPOS, Gastão Wagner de Sousa. Reforma da reforma: repensando a saúde. 2. ed. Hucitec: São Paulo, 1997. p. 137.

${ }^{46}$ LUHMANN, Niklas. O paradoxo dos direitos humanos e três formas de seu desmembramento. Themis, Fortaleza, v. 3, n.1, p. 158, 2000.

${ }^{47}$ Id. A posição dos Tribunais no sistema jurídico. Revista da Ajuris, Porto Alegre, p. 149-168, jul. 1990.

${ }^{48}$ SCHWARTZ, Germano; FLORES, Luis Gustavo Gomes. O direito como controle do tempo (ou como controle temporal do direito): a quem o abril despedaçou? In: ROCHA, Leonel Severo; Francisco Carlos Duarte (Orgs.). A construção sociojurídica do tempo. Curitiba: Juruá, 2012. p. 55

${ }^{49}$ LUHMANN, Niklas. Das Recht der Gesellschaft, cit., p. 558.
} 
CAMPOS, Gastão Wagner de Sousa. Reforma da reforma: repensando a saúde. 2. ed. Hucitec: São Paulo, 1997.

CLAM, Jean. Questões Fundamentais de uma teoria da sociedade: contingência, paradoxo, só-efetuação. São Leopoldo: Ed. Unisinos, 2006.

DE GIORGI, Rafaelle. Direito, tempo e memória. São Paulo: Quartier Latin, 2006.

KELSEN, Hans. Teoria pura do direito. 6. ed. São Paulo: Martins Fontes, 1998.

LUHMANN, Niklas. Das Recht der Gesellschaft. Frankfurt: Suhrkamp, 1997. . Introduccíon a la teoría de sistemas. México: Universidad Iberoamericana, 2004. . Legitimação pelo procedimento. Brasília: Ed. da UnB, 1980.

. O paradoxo dos direitos humanos e três formas de seu desmembramento. Themis, Fortaleza, v. 3, n.1, p. 153-161, 2000.

. A posição dos Tribunais no sistema jurídico. Revista da Ajuris, Porto Alegre, p. 149-168, jul. 1990.

- A restituição do décimo segundo camelo: do sentido de uma análise sociológica do direito. In: ARNAUD, André-Jean; LOPES JR., Dalmir (Orgs.). Niklas Luhmann: do sistema social à sociologia jurídica. Rio de Janeiro: Lumen Juris, 2004. p. 33-108.

. Sistemas sociales: lineamientos para una teoría general. México: Alianza; Universidad Iberoamericana, 1991.

. La sociedad de la sociedad. México: Herder, 2007.

. Sociologia do direito I. Rio de Janeiro: Tempo Brasileiro, 1983.

. Sociologia del riesgo. México: Triana, 1993.

. Sociologische Aufklärung 5: konstruktivistische perspektiven. Opladen: Westedeutscher Verlag, 1993.

System as difference. Organization, London, v. 13, n. 1, p. 37-57, 2006.

Therapeutische Systeme - Fragen an Niklas Luhmann. In: SIMON, F.B. (Hg.). Lebende Systeme. Wirklichkeistskonstruktionen in der Systemichen Therapie. Berlin: Heidelberg - New York u.a., 1988. p. 124-138.

MENDES, Gilmar Ferreira. Introdução. Audiência Pública - Saúde. Brasília: Supremo Tribunal Federal, 2009.

MOREAU, Jacques; TRUCHET, Didier. Droit de la santé publique. Paris: Dalloz, 2000.

OST, François. O tempo do direito. Lisboa: Piaget, 1999. 
ROCHA, Leonel Severo. A construção do tempo pelo direito. In: ROCHA, Leonel Sevro; STRECK, Lenio Luiz (Orgs.). Anuário do Programa de Pós-Graduação em Direito. Mestrado e Doutorado. 2003. São Leopoldo: Unisinos, 2003. p. 309-320.

; Francisco Carlos Duarte. O direito e o tempo social. In: ROCHA, Leonel Severo; Francisco Carlos Duarte. (Orgs.). A construção sociojurídica do tempo. Curitiba: Juruá, 2012. p. 15-34.

SCAFF, Fernando Facury. O direito à saúde e os Tribunais. In: NUNES, Antônio José Avelãs; SCAFF, Fernando Facury (Orgs.). Os Tribunais e o direito à saúde. Porto Alegre: Livr. do Advogado, 2011.

SCHWARTZ, Germano. A autopoiese do sistema sanitário. Revista de Direito Sanitário, São Paulo, v. 4, n. 1, p. 50-59, 2003.

Direito à saúde: efetivação em uma perspectiva sistêmica. Porto Alegre: Livr. do Advogado, 2001.

Gestão compartida sanitária no Brasil: possibilidade de efetivação do direito à saúde. In: SCHWARTZ, Germano (Org). A saúde sob os cuidados do direito. Passo Fundo: UPF Ed., 2003. p. 108-162.

; FLORES, Luis Gustavo Gomes. O direito como controle do tempo (ou como controle temporal do direito): a quem o abril despedaçou? In: ROCHA, Leonel Severo; Francisco Carlos Duarte (Orgs.). A construção sociojurídica do tempo. Curitiba: Juruá, 2012. p. 35-62.

SOUZA, Renildo Rehem. O sistema público de saúde brasileiro. Brasília: Ministério da Saúde, 2002.

TEUBNER, Gunther. O direito como sistema autopoiético. Lisboa: Calouste Gulbenkiam, 1989.

TOJAL, Sebastião Botto de Barros. O direito regulatório do Estado Social e as normas legais de saúde pública. Brasília: Organização Pan-Americana de Saúde: Escritório Regional da Organização Mundial de Saúde: Representação do Brasil, 1994. p 15-23. (Série Direito e Saúde, n. 4).

VALLE, Gustavo Henrique Moreira do; CAMARGO, João Marcos Pires. A audiência pública sobre a judicialização da saúde e seus reflexos na jurisprudência do Supremo Tribunal Federal. Revista de Direito Sanitário, São Paulo, v. 11, n. 3, p. 13-31, nov. 2010/fev. 2011.

Germano André Doederlein Schwartz - Pós-Doutor em Direito pela University of Reading; Doutor em Direito pela Universidade do Vale do Rio dos Sinos com estágio-sanduíche na Université Paris X (Nanterre). Coordenador do Mestrado em Direito e docente colaborador do Mestrado em Saúde e Desenvolvimento Humano do Centro Universitário La Salle; Professor do Curso de Graduação em Direito do Centro Universitário La Salle; Diretor Executivo Acadêmico dos Cursos de Direito da Faculdades Metropolitanas Unidas. Secretário do Research Committee on Sociology of Law da International Sociological Association; Membro do Executive Committee do World Consortium on Sociology of Law; Segundo Vice-Presidente da Associação Brasileira de Pesquisadores em Sociologia do Direito. Porto Alegre/RS, Brasil. E-mail: germano.schwartz@globo.com. 